\title{
Sistem Informasi AKUNTER (Akuntansi Terpadu) Berbasis Web Sebagai Pengelolaan Transaksi Keuangan Pada Mutiara Laundry
}

\author{
Muhamad Nasihin" ${ }^{\# 1}$, Yulia ${ }^{\# 2}$, Nanda Diaz Arizona ${ }^{\# 3}$

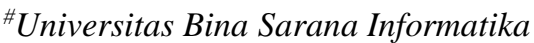 \\ Jalan Abdurahman Saleh No. 18 Pontianak \\ ${ }^{1}$ muhamad.mhnebsi.ac.id \\ ${ }^{2}$ yulia.yla@bsi.ac.id \\ ${ }^{3}$ nanda.ndz@bsi.ac.id
}

\begin{abstract}
Abstrak- Mutiara Laundry adalah usaha jasa cuci pakaian kiloan di Sui Raya Dalam Kabupaten Kubu Raya. Jenis penelitian menggunakan studi kasus dengan cara wawancara kepada pemilik usaha laundry yaitu bapak Romi. Seiring berkembangnya usaha dan juga persaingan laundry yang semakin banyak maka diperlukan pengelolaan keuangan mutiara laundry agar lebih teratur. Penulis merancang sistem informasi Akunter (Akuntansi Terpadu) berbasis web yang bertujuan untuk memudahkan pemilik untuk mengelola keuangan laundry, salah satunya dapat meminimalisir hilangnya bukti transaksi. Dalam sistem pengelolaan keuangan tersebut terdapat transaksi harian, pesanan laundry, hasil penjualan produk seperti detergen cair, parfum mobil softener, pewangi pakaian sampai laporan akhir bulan Mutiara Laundry. Aplikasi ini dibuat menggunakan struktur website HTML dan MySQL. Hasil penelitian menampilkan laporan penjualan, laporan penjualan reseller dan laporan laundry.
\end{abstract}

Kata kunci : Akunter (Akuntansi Terpadu), Laundry, Web

\section{Pendahuluan}

Pelayanan pada bisnis laundry mengalami persaingan antar usaha sejenis. Berbagai jenis laundry menawarkan produknya untuk memperoleh kepercayaan terhadap pelanggan dengan memberikan kualitas yang terbaik. Pelanggan menginginkan pelayanan servis yang didapatkan sesuai dengan kualitas yang dijanjikan oleh penyedia jasa laundry. Dengan banyaknya usaha laundry yang semakin menjamur, maka diperlukan pemasaran yang ekstra yang membuat pelanggan tertarik untuk menitipkan pakaiannya ke laundry. Umumnya laundry tersebut memasarkan usahanya dengan mengandalkan usaha informasi dari mulut ke mulut dari konsumennya. Begitu juga dengan Mutiara Laundry, industry rumah tangga ini sudah berjalan dari tahun 2013.

Mutiara laundry merupakan usaha rumahan yang bergerak dibidang jasa pencucian dan menyetrika pakaian di daerah Sei Raya Dalam Kabupaten Kubu Raya. Mutiara laundry juga menciptakan produk deterjen cair, parfum mobil, softener yang dapat menjangkau segmentasi pasar. Diketahui omset Mutiara Laundry per hari dapat mencapai 150 kg-an pakaian. Ini tentu saja membutuhkan pengelolaan keuangan yang baik. Agar usaha dapat berjalan dengan baik dan sukses tentunya tidak hanya dibutuhkan kreatifitas saja, ilmu dan pengetahuan yang luas serta kemampuan tata kelola yang baik merupakan faktor penting yang bisa menjadi bekal untuk mengembangkan bisnis yang telah dijalankan maupun yang masih baru. [1]

Selama ini pengeluaran berupa pembelian bahan pembuatan detergen cair, softener, pewangi pakaian, biaya listrik, tabung gas dan gaji karyawan masih menggunakan pencatatan melalui media kertas. [4] Melihat kondisi tersebut penulis memberikan solusi pengelolaan keuangan Mutiara Laundry dapat dibuat dengan berbasis web agar mempermudah dalam pencatatan transaksi yang dapat digunakan disemua perangkat elektronik yang terhubung dengan internet. [10]

Dalam pengelolaan keuangan berbasis web ini akan semakin memudahkan Mutiara Laundry dalam meningkatkan omsetnya, dengan melihat transaksi harian, pemesanan laundry, hasil penjualan produk seperti detergen cair, parfum mobil, softener, pewangi pakaian sampai laporan akhir bulan Mutiara Laundry seperti laporan penjualan, laporan penjualan reseller dan laporan laundry.

\section{Metode Penelitian}

Menurut Sugiyono dalam (Darna \& Herlina, 2018) adalah "cara-cara ilmiah untuk mendapatkan data yang valid, dengan tujuan dapat ditemukan, dikembangkan dan dibuktikan, suatu pengetahuan tertentu sehingga pada gilirannya dapat digunakan untuk memahami, memecahkan, dan mengantisipasi masalah." [2] Metode dapat dipahami sebagai tata cara bagaimana suatu penelitian dilaksanakan. [3] Penelitian ini menggunakan 
studi kasus dengan teknik pengumpulan data, sebagai berikut [4] :

1) Pengamatan (Observation): Penulis melakukan pengamatan secara langsung ke lokasi penelitian yaitu melihat langsung proses pengelolaan keuangan pada Mutiara Laundry yang beralamat di Jalan Sei Raya Dalam Kabupaten Kubu Raya Dalam. Komplek Srikandi 1 Asabri No. 15 RT. 003 RW. 023 Kelurahan Sei Raya Dalam Kabupaten Kubu Raya.

2) Wawancara (Interview): Penulis menggunakan metode tanya jawab kepada Bapak Romi selaku pemilik Mutiara Laundry. Diketahui pencatatan pengelolaan keuangan dilakukan manual dengan media kertas.

3) Studi pustaka: Studi pustaka menggunakan beberapa literatur dikumpulkan dari berbagai sumber jurnal, buku, maupun referensi sistem informasi pengelolaan keuangan yang dapat ditemukan di internet.

\section{HASIL DAN PEMBAHASAN}

\section{A. Proses Bisnis Berjalan}

Berdasarkan ruang lingkup yang telah dijabarkan, berikut akan disajikan proses bisnis sistem berjalan pada Mutiara Laundry.

1) Proses pelayanan laundry: Tahap pertama pelanggan datang ke laundry dan menyerahkan baju kotornya, kemudian karyawan akan menerima dan menimbangnya, setelah itu karyawan mencatat nota yang berisi nama, alamat, telepon, tanggal masuk pakaian, tanggal selesai pakaian, dan uraian pakaian yang ditimbang. Setelah selesai mencatat semua karywan memberikan nota kepada pelanggan untuk bukti pengambilan pakaian yang telah selesai dilaundry dan nota satunya lagi diarsipkan sebagai bukti transaksi pemasukan keuangan Mutiara Laundry.

2) Proses persedian bahan: Karyawan mengecek persediaan barang apakah masih ada atau sudah habis, setelah dicek ternyata sebagian bahan ada yang sudah habis. Kemudian karyawan mencatat bahan-bahan yang habis dan memberitahukan kepada pemilik laundry agar pemilik langsung membeli bahan-bahan yang habis tadi, setelah pemilik membeli bahan-bahan tersebut, kemudian bahan tersebut dikelolah dan diproses untuk dijual kembali.

\section{B. Analisa Kebutuhan Fungsional}

Perangkat lunak dapat dilihat dari kebutuhan user, maka dapat dikatakan baik dan sangat tergantung dari analisa kebutuhannya[5]. Analisa sistem ini sangat dibutuhkan dalam mengidentifikasi data dan proses yang dibutuhkan sistem[6]. Sistem yang akan digunakan disesuaikan dengan kebutuhan Mutiara Laundry, maka terdapat beberapa kebutuhan dalam mengolah data pengguna, data paket, data produk, data pelanggan, data laundry, data penjualan, data transaksi samapi dihasilkannya laporan. Program yang dibuat dapat digunakan oleh pemilik dan karyawan dengan tujuan untuk membantu dan mempermudah transaksi pengelolaan keuangan laundry agar lebih efektif dan efisien dalam transaksi dan penyimpanan data. [16]

Analisa penulis pada sistem pengelolaan keuangan pada Mutiara Laundry Jalan Sui Raya Dalam, antara lain :

1. Pemilik

a) Pemilik dapat melakukan login.

b) Pemilik dapat mengakses menu home.

c) Pemilik dapat mengakses master data.

- Pemilik dapat mengakses pengguna.

- Pemilik dapat mengakses paket laundry.

- Pemilik dapat mengakses produk.

- Pemilik dapat mengakses pelanggan.

d) Pemilik dapat mengakses data laundry.

e) Pemilik dapat mengakses penjualan.

- Pemilik dapat mengakses penjualan biasa.

- Pemilik dapat mengakses penjualan reseller.

f) Pemilik dapat mengakses laporan.

- Pemilik dapat mengakses hasil laporan laundry.

- Pemilik dapat mengakses laporan penjualan reseller.

- Pemilik dapat mengakses laporan Penjualan.

g) Pemilik dapat melakukan logout.

2. Karyawan

a) Karyawan dapat melakukan login.

b) Karyawan dapat mengakses menu home.

c) Karyawan dapat mengakses master data.

- Karyawan dapat mengakses pengguna.

- Karyawan dapat mengakses paket laundry.

- Karyawan dapat mengakses produk.

- Karyawan dapat mengakses pelanggan.

d) Karyawan dapat mengakses data laundry.

e) Karyawan dapat mengakses penjualan.

- Karyawan dapat mengakses penjualan biasa.

- Karyawan dapat mengakses penjualan reseller.

f) Karyawan dapat melakukan logout.

\section{Use Case Diagram}

Use case diagram ialah pemodelan yang digunakan untuk menggambarkan kelakuan sistem yang akan dibuat, prosedur bisnis dan juga urutan kegiatan yang ada dalam sebuah proses dan mendeskripsikan sebuah kontak antara satu atau lebih aktor dengan sistem yang akan dibuat. [7]

Use case diagram menjelaskan fungsi yang ada didalam sebuah sistem dan user yang menggunakan fungsi-fungsi tersebut. [8]

Berikut use case diagram beranda pada sistem informasi beranda pada Mutiara Laundry. 


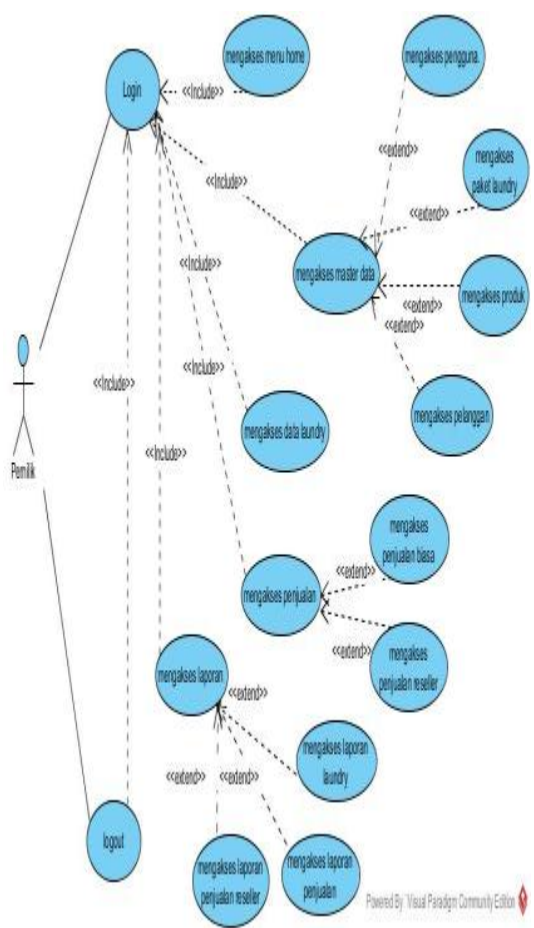

Sumber : Rancangan, 2020

Gambar 1. Use case diagram beranda pemilik

TABEL I

SKENARIO USE CASE DIAGRAM BERANDA PEMILIK

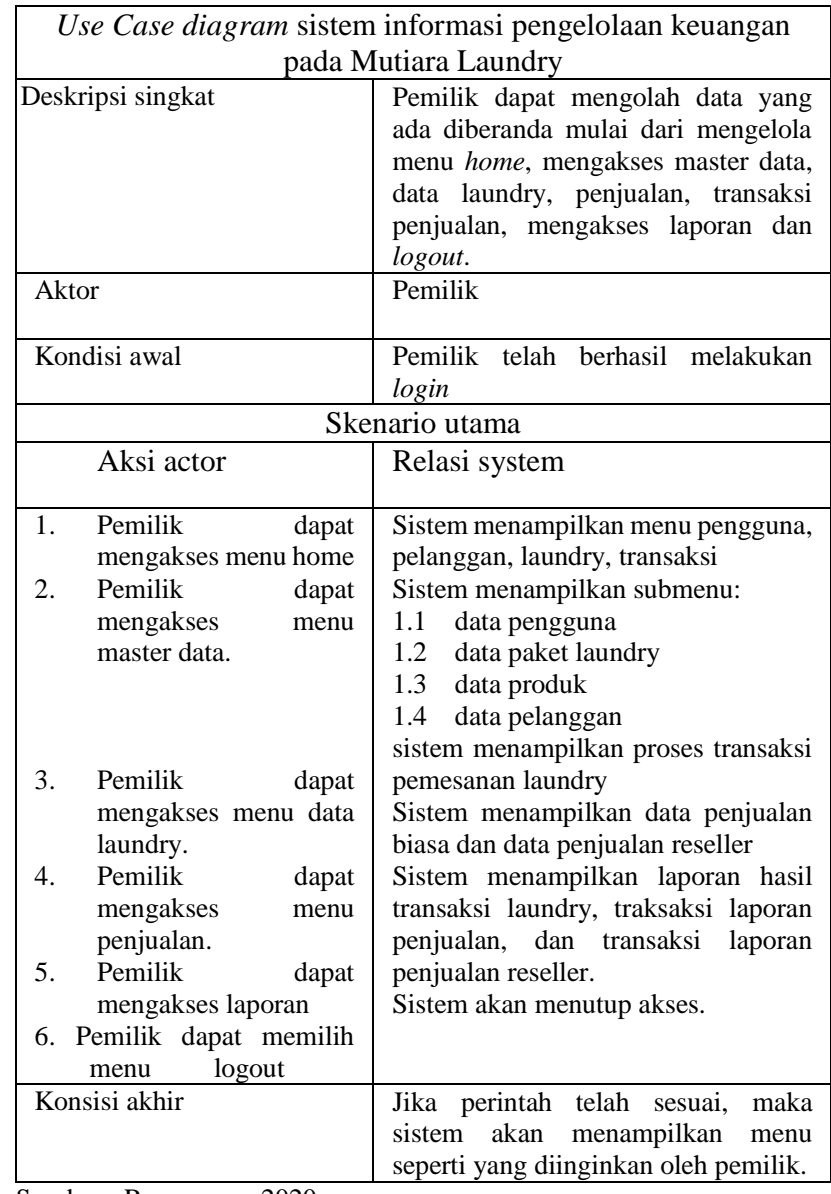

Sumber : Rancangan, 2020

\section{Activity Diagram}

Activity diagram ini menggambarkan tentang aktifitas yang terjadi pada sistem [9]. Diagram menunjukkan langkah - langkah dalam proses kerja sistem yang dibuat dari pertama sampai akhir, [16]

Dibawah ini merupakan Activity diagram sistem informasi pengelolaan keuangan pada Mutiara Laundry.

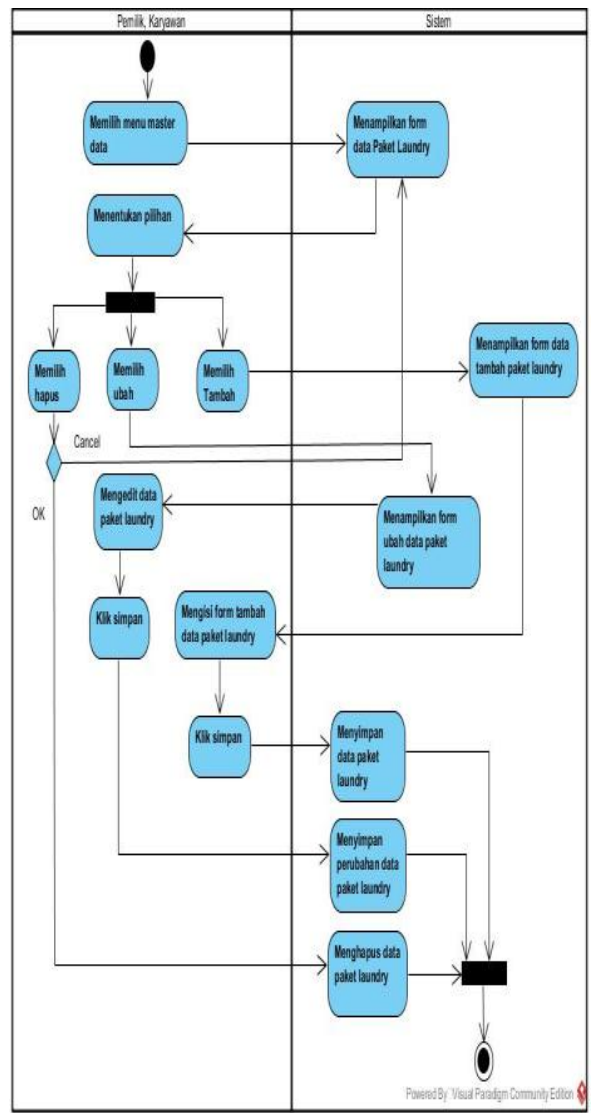

Sumber : Rancangan, 2020

Gambar 2 Activity diagram data paket laundry sistem pada mutiara laundry

Pada activity diagram data paket laundry sistem ini menjelaskan, dimana pemimpin dan karyawan dapat menambahkan, mengubah dan hapus data ke dalam sistem.

\section{E. Sequence Diagram}

Sequence diagram merupakan satu dari diagramdiagram yang ada pada UML, sequence diagram ini adalah diagram yang menggambarkan hubungan dinamis antara sejumlah object. Fungsinya untuk menunjukkan rangkaian pesan yang dikirim antara object juga interaksi antara object. [10] 


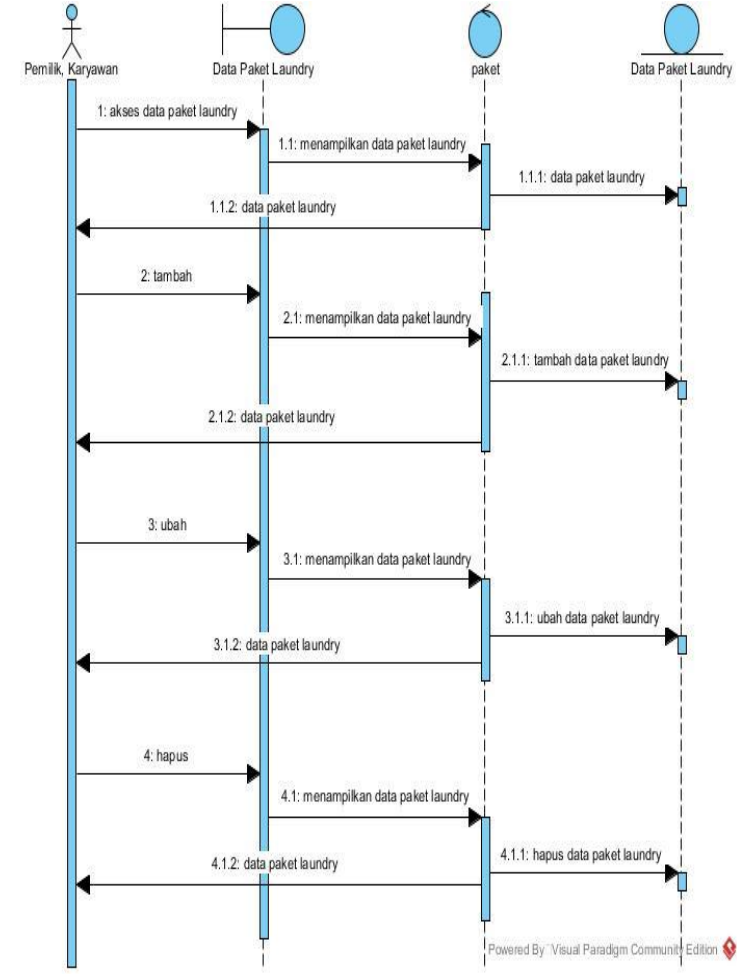

Sumber : Hasil Rancangan, 2020.

Gambar 3 Sequence diagram data paket laundry pada mutiara laundry

Pada sequence diagram data paket laundry menggambarkan dimana karyawan dan pemilik mengakses menu transaksi data paket laundry, sistem akan menampilkan data paket laundry. Karyawan dan pemilik juga dapat menambahkan, ubah dan hapus data paket laundry.

\section{F. Class Diagram}

Class diagram merupakan diagam yang digunakan untuk menampilkan beberapa kelas serta paket-paket yang ada dalam sistem/perangkat lunak. [11]

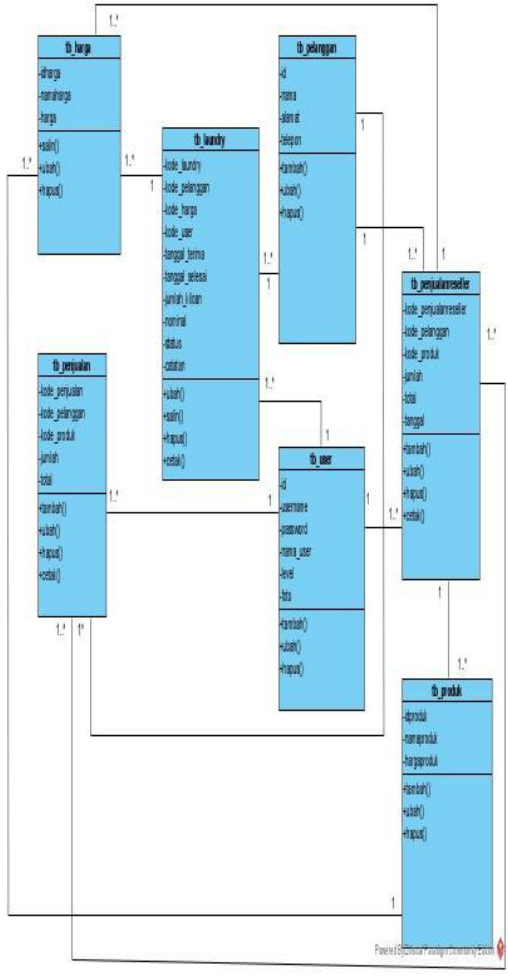

Sumber : Hasil Rancangan, 2020

Gambar. 4 Class diagram sistem pada mutiara laundry

Pada Class Diagram paket laundry terdapat model desain system yang menampilkan aturan dan tanggung jawab entitas yang menentukan perilaku system.

\section{G. User Interface}

User Interface ialah tampilan yang bersinggungan langsung dengan user dan memiliki fungsi untuk menghubungkan antara user dengan sistem operasi sehingga aplikasi dapat dioperasikan. [12]

1. User Interface Form Login

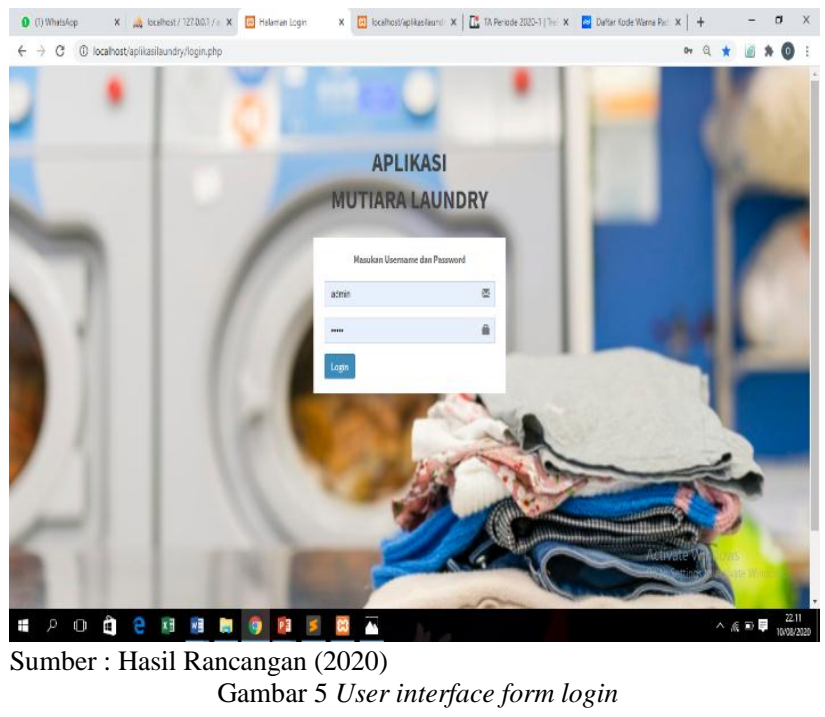

Pada User Interface Form Login, pengguna dapat masuk dengan mengisi username dan password. 
2. User Interface Beranda Home Pemilik

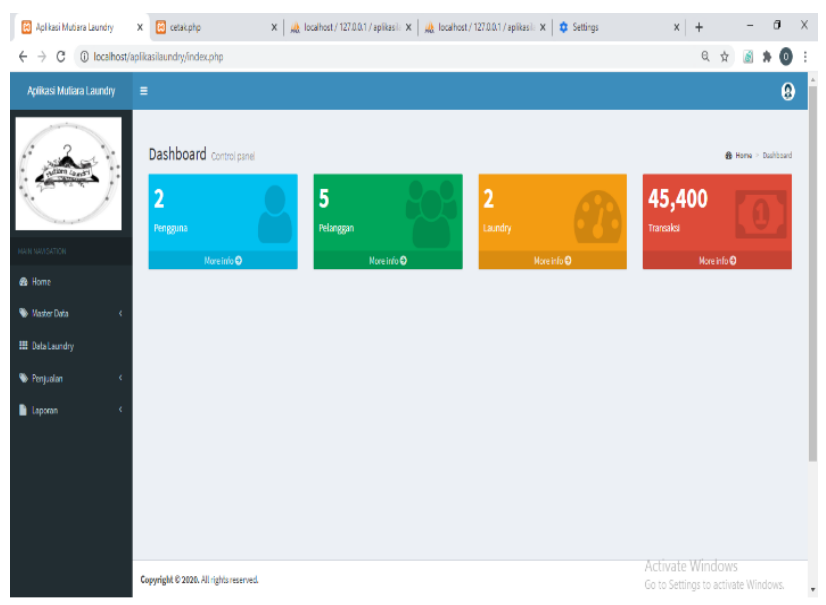

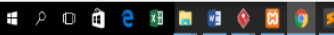

Sumber : Hasil Rancangan (2020)

Gambar 6 User interface beranda home pemilik

Pada User Interface Beranda Home Pemilik terdapat tampilan dashboard yang menampilkan rekap akses pengguna, pelanggan, jumlah laundry dan transaksi pada periode yang ingin ditampilkan (contoh : hari/minggu/bulan),

3. User Interface Tampilan Data Pengguna

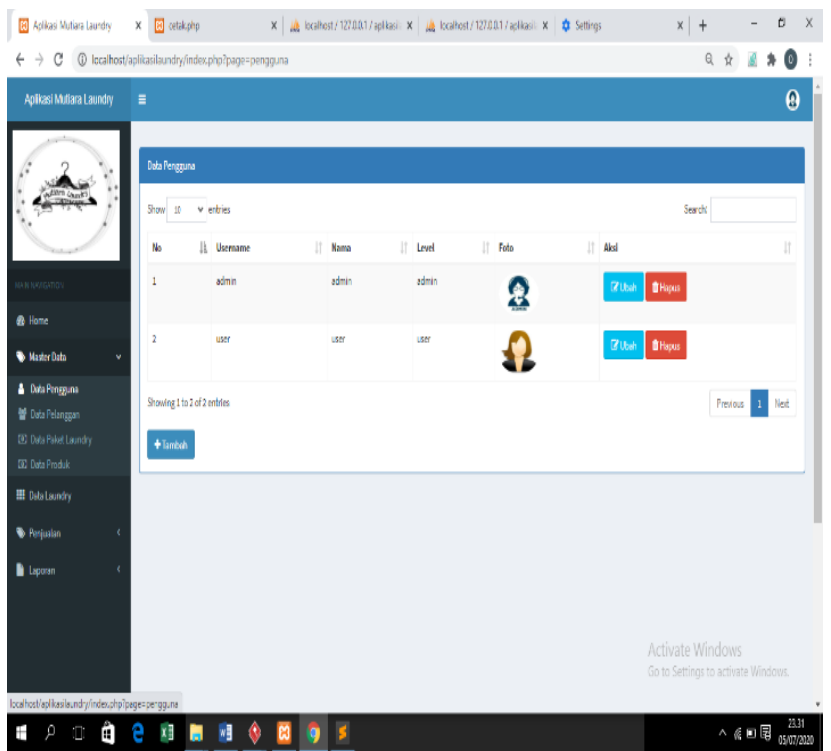

Sumber : Hasil Rancangan (2020)

Gambar 7 User interface data pengguna

Pada User Interface Tampilan Data Pengguna muncul username, nama, level, foto dan aksi.
4. User Interface Data Paket Laundry

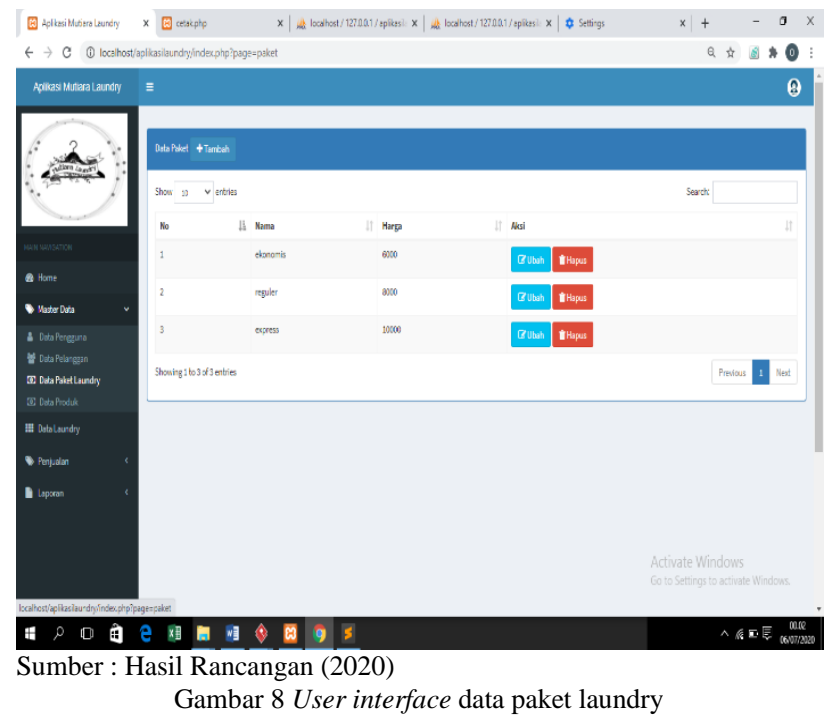

Pada User Interface Data Paket Laundry muncul pilihan paket, harga dan aksi.

5. User Interface Data Produk

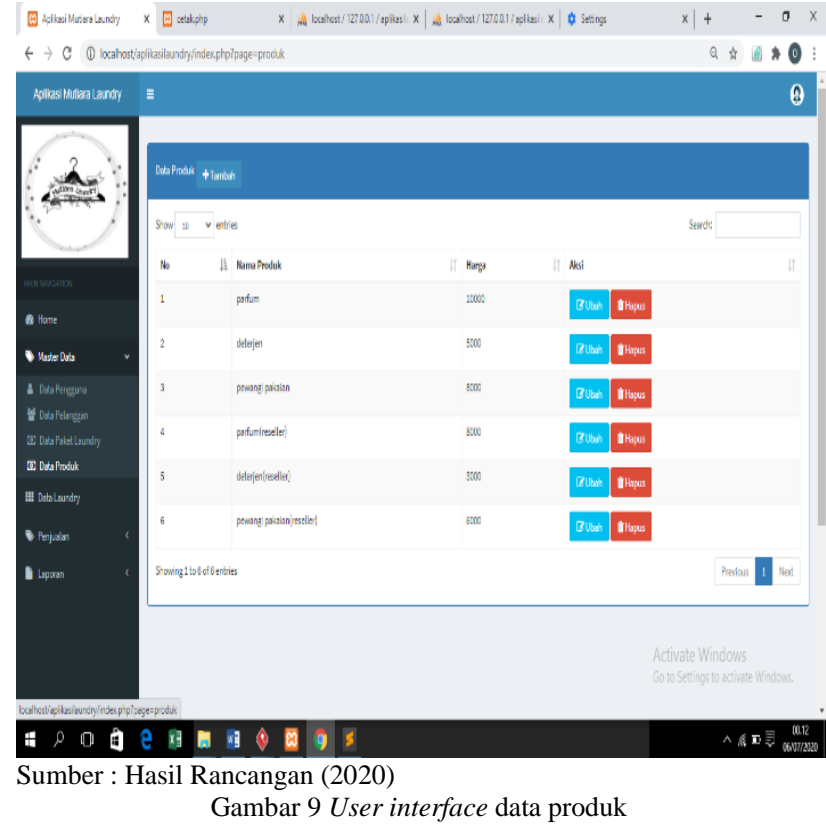

Pada User Interface Data Produk tampil nama produk, harga dan aksi. 
6. User Interface Cetak Penjualan Biasa

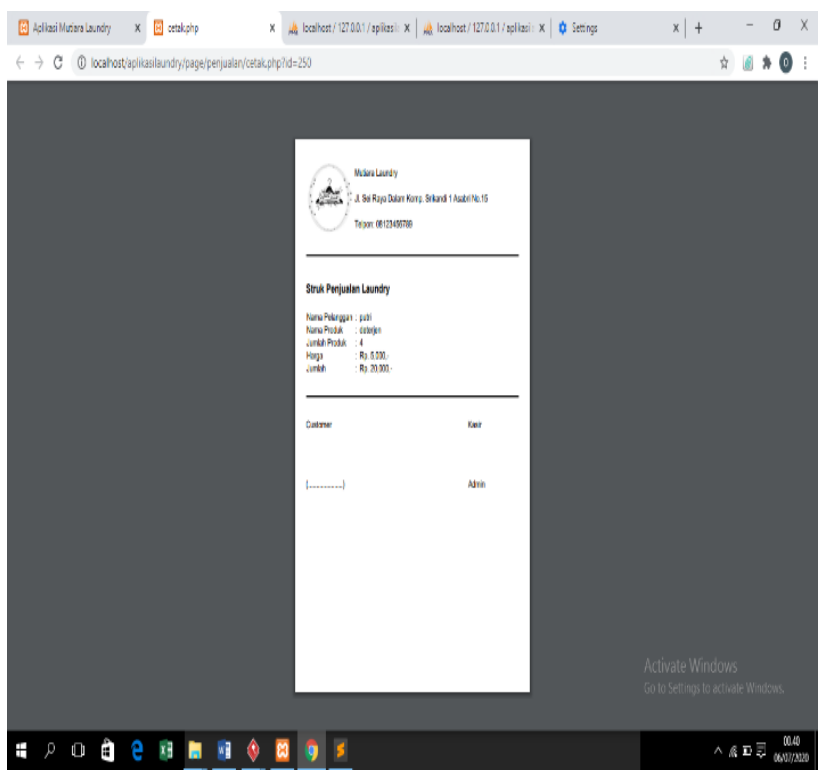

Sumber : Hasil Rancangan (2020)

Gambar 10 User interface cetak penjualan biasa

Pada User Interface Cetak Penjualan Biasa muncul struk penjualan produk/jasa laundry.

7. User Interface Cetak Laporan Penjualan

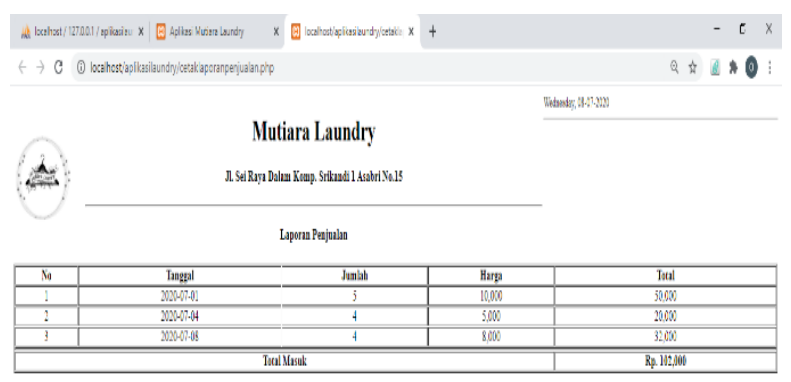

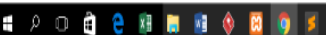

Sumber : Hasil Rancangan (2020)

Gambar 11 User interface cetak laporan penjualan

Pada User Interface Cetak Laporan Penjualan muncul laporan pendapatan Mutiara Laundry, yang terdiri dari tanggal terima laundry, tanggal selesai, jumlah kiloan, produk, dan nominal.

\section{H. Blackblock Testing}

Blackbox testing ialah memeriksa fungsional dari perangkat lunak dengan melakukan pengamatan hasil eksekusi data uji.[13] Berikut merupakan black box testing sistem informasi penjualan dan pembelian.
TABEL III

Hasil Pengujian Blackbox TeSTING MenCETAK LAPORAn LAUNDRY

\begin{tabular}{|c|l|l|l|c|c|}
\hline No & $\begin{array}{c}\text { Skenario } \\
\text { Pengujian }\end{array}$ & $\begin{array}{c}\text { Test } \\
\text { Case }\end{array}$ & $\begin{array}{l}\text { Hasil Yang } \\
\text { Diinginkan }\end{array}$ & $\begin{array}{c}\text { Hasil } \\
\text { Pengujian }\end{array}$ & $\begin{array}{c}\text { Kesi } \\
\text { mpul } \\
\text { an }\end{array}$ \\
\hline 1. & $\begin{array}{l}\text { Memilih } \\
\text { periode } \\
\text { bulanan, } \\
\text { kemudian } \\
\text { klik“ } \\
\text { Cetak } \\
\text { Laporan" }\end{array}$ & $\begin{array}{l}\text { Mence } \\
\text { tak }\end{array}$ & $\begin{array}{l}\text { Sistem akan } \\
\text { menerima dan } \\
\text { data penjualan } \\
\text { akan tercetak } \\
\text { di laporan } \\
\text { Laundry }\end{array}$ & $\begin{array}{c}\text { Sesuai } \\
\text { Harapan }\end{array}$ & Valid \\
& & & & \\
& & & & \\
\hline
\end{tabular}

Sumber : Hasil Rancangan, 2020

TABEL IIIII

HASIl PENGUJian BlackBox TESTING MENCETAK LAPORAN PENJUALAN

\begin{tabular}{|c|c|c|c|c|c|}
\hline No & $\begin{array}{l}\text { Skenario } \\
\text { Pengujia } \\
n\end{array}$ & $\begin{array}{l}\text { Test } \\
\text { Case }\end{array}$ & $\begin{array}{l}\text { Hasil } \\
\text { Yang } \\
\text { Diharapk } \\
\text { an } \\
\end{array}$ & $\begin{array}{l}\text { Hasil } \\
\text { Pengujia } \\
\mathrm{n}\end{array}$ & $\begin{array}{l}\text { Kesimpul } \\
\text { an }\end{array}$ \\
\hline 1 & $\begin{array}{l}\text { Memilih } \\
\text { periode } \\
\text { bulanan, } \\
\text { kemudia } \\
\text { n } \\
\text { klik"Ceta } \\
\text { k } \\
\text { Laporan" }\end{array}$ & $\begin{array}{l}\text { Menceta } \\
\mathrm{k}\end{array}$ & $\begin{array}{l}\text { Sistem } \\
\text { akan } \\
\text { menerima } \\
\text { dan data } \\
\text { penjualan } \\
\text { akan } \\
\text { tercetak di } \\
\text { laporan } \\
\text { penjualan }\end{array}$ & $\begin{array}{l}\text { Sesuai } \\
\text { Harapan }\end{array}$ & Valid \\
\hline
\end{tabular}

TABEL IVY

Hasil Pengujian Blackbox Testing Mencetak Laporan PENJUALAN RESELLER

\begin{tabular}{|c|c|c|c|c|c|}
\hline No & $\begin{array}{l}\text { Skenario } \\
\text { Pengujia } \\
\mathrm{n}\end{array}$ & $\begin{array}{l}\text { Test } \\
\text { Case }\end{array}$ & $\begin{array}{l}\text { Hasil } \\
\text { Yang } \\
\text { Diharapk } \\
\text { an }\end{array}$ & $\begin{array}{l}\text { Hasil } \\
\text { Pengujia } \\
\mathrm{n}\end{array}$ & $\begin{array}{l}\text { Kesimpul } \\
\text { an }\end{array}$ \\
\hline $\begin{array}{l}1 \\
. \quad\end{array}$ & $\begin{array}{l}\text { Memilih } \\
\text { periode } \\
\text { bulanan, } \\
\text { kemudia } \\
\text { n } \\
\text { klik"Ceta } \\
\text { k } \\
\text { Laporan" }\end{array}$ & $\begin{array}{l}\text { Menceta } \\
\mathrm{k}\end{array}$ & $\begin{array}{l}\text { Sistem } \\
\text { akan } \\
\text { menerima } \\
\text { dan data } \\
\text { penjualan } \\
\text { akan } \\
\text { tercetak di } \\
\text { laporan } \\
\text { penjualan } \\
\text { Reseller }\end{array}$ & $\begin{array}{l}\text { Sesuai } \\
\text { Harapan }\end{array}$ & Valid \\
\hline
\end{tabular}

\section{Spesifikasi Hardware Dan Software}

Gabungan dari beberapa peralatan komputer yang saling berhubungan disebut sistem komputer. Komputer merupakan unsur dasar sebagai fasilitas yang harus ada ketika suatu usaha mengalami kemajuan dengan mengunakan komputer sebagai alat bantu dalam pengolahan data. [14]. Agar sistem informasi akuntansi terpadu (Akunter) dapat berjalan seperti yang diharapkan, maka perlu diperhatikan aspek-aspek hardware dan software sebagai berikut : 
TABEL VV

SPEFIKASI PERANGKAT YANG DIGUNAKAN

\begin{tabular}{|c|c|}
\hline Kebutuhan & Keterangan \\
\hline Sistem & Windows 7 32-bit \\
\hline Processor & $\begin{array}{l}\text { Intel } \AA \text { Celeron } ® \text { processor } 1019 \mathrm{Y}(1.0 \mathrm{GHz}, 2 \mathrm{MB} \\
\text { cache) }\end{array}$ \\
\hline RAM & $2 \mathrm{~Gb}$ \\
\hline Harrdisk & $500 \mathrm{~GB}$ \\
\hline Monitor & 12 "' LED \\
\hline Keyboard & 108 Key \\
\hline Printer & Cannon IP 2770 \\
\hline Mouse & Standard \\
\hline Software & $\begin{array}{l}\text { Sistem Operasi : Windows } 7 \\
\text { Bahasa Script Programming : PHP } \\
\text { Web Server : XAMPP } \\
\text { DBSM : SQL } \\
\text { Web Browser : Mozilla Firefok, Google Chrome. }\end{array}$ \\
\hline
\end{tabular}

Sumber : Hasil Rancangan (2020)

\section{KESIMPULAN}

1. Sistem dan pengelolaan keuangan pada Mutiara Laundry ini masih menggunakan tulis tangan sehingga masih banyak ditemukan masalah yang mengakibatkan kesalahan dalam pencatatan, hilangnya data dan sulitnya pencarian nota-nota penjualan pada Mutiara Laundry. Dalam sistem informasi AKUNTER terdapat transaksi harian, pesanan laundry, hasil penjualan produk seperti detergen cair, parfum mobil softener, pewangi pakaian sampai laporan akhir bulan Mutiara Laundry. Laporan yang dihasilkan antara lain laporan penjualan, laporan penjualan reseller dan laporan laundry.

2. AKUNTER dirancang untuk dikelola oleh pemilik dan karyawan laundry untuk mempermudah dalam melakukan transaksi pengelolaan keuangan, karena dapat meminimalisir kesalahan dalam pencatatan dan kehilangan berkas. Ini dibuktikan dengan pencatatan transaksi yang lebih cepat dengan menggunakan web dan penyajian laporan bulanan yaitu laporan penjualan, laporan penjualan reseller, dan laporan laundry.

\section{REFERENSI}

[1] Putri, Mediany Kriseka dan Angga Dwi Utama. 2017. Evaluasi Model Bisnis Pada Laundry Bar Dengan Pendekatan Business Model Canvas. Jurnal Manajemen Indonesia. Vo. 17 (2). ISSN : 2502-3713.

[2] Darna, N., \& Herlina, E. (2018). Memilih Metode Penelitian Yang Tepat: Bagi Penelitian Bidang Ilmu Manajemen. Jurnal Ilmu Manajemen, $5(1)$, https://doi.org/10.2827/jeim.v5i1.1359.

[3] Supardi. 2005. Metodologi Penelitian Ekonomi dan Bisnis, (Cet. I; Yogyakarta: UII Press.

[4] Hasrina, Y. (2015). Analisis Pengelolaan Keuangan Rural Infrastucture Support Program Nasional Pemberdayaan Masyarakat (Ris-Pnpm) Di Organisasi Masyarakat Setempat
(Oms) Kecamatan Tuah Negeri Kabupaten Musi Rawas. 13. https://media.neliti.com/media/publications/283870-analisispengelolaan-keuangan-rural-infr-403bc91b.pdf.

[5] Prasetya, W. S. (2015). Perancangan Model Basis Data Relasional Dengan Metode Database Life Cycle. Prosiding Seminar Nasional Informatika 2015, 91-98.

[6] Rengkung, R., Sentinuwo, S. R., \& Karouw, S. (2015). Pembangunan Sistem Informasi Repository Berbasis Teknologi Web Component Studi Kasus GMIM Bukit Moria Winangun. EJournal Teknik Elektro Dan Komputer, 1-6(6), 56-61

[7] Fridayanthie, E. W. (2015). Perancangan Sistem Informasi Penjualan Peralatan Hiking Berbasis Dekstop Pada Toko Cimone Outdoor Tangerang. Jurnal Khatulistiwa Informatika, 3(2), 144.

[8] Nasihin, Muhamad. 2019. Rancang Bangun Sistem Informasi Point of Sales (POS) Pada CV. Arema Alam Abadi. Jurnal Teknologi dan Manajemen Informatika. ISSN 2580-8044.

[9] ND Arizona, Yulia, R. Saputra. "Aplikasi Pengolahan Data Penerimaan dan Pengeluaran Kas Pada SMK Cahaya Bangsa Kabupaten Kubu Raya." Pilar Nusa Mandiri (2018): 253-260.

[10] Irmayani, Windi, dkk. (2020). Pengelolaan Keuangan Berbasis Web PT. Mutualplus Global Resources Cabang Pontianak. Jurnal Sistem Informasi Akuntansi Vol. 01, No. 01, Maret 2020, pp. 4049. Retrieved from https://ejournal.bsi.ac.id/ejurnal/index.php/j ustian/article/view/7975.

[11] Nasihin, M., \& Adwiya, R. (2018). Sistem Informasi Pengaduan Masyarakat Kecamatan Pontianak Selatan. Cybernetics, 2 (1), 144 154. https://doi.org/10.29406/cbn.v2i1.959.

[12] Yulia, dkk. 2020. Sistem Informasi Penjualan Produk Pontimarket. JURNAL KHATULISTIWA INFORMATIKA, VOL. VIII, NO. 1 JUNI 2020. p-ISSN: 2339-1928 I e-ISSN: 2579-633X

[13] Jaya, Tri Snadhika. 2018. Pengujian Aplikasi dengan Metode Blackbox Testing Boundary Value Analysis (Studi Kasus: Kantor Digital Politeknik Negeri Lampung). Jurnal Informatika: Jurnal Pengembangan IT (JPIT), Vol.03, No.02. ISSN: 2477-5126.

[14] Irmayani, W., Yulia, Y., \& Erni, E. (2019). Laporan Akhir Penelitian: Sistem Pengolahan Data APBDes (SIPDABDES) Pada Kantor Desa Wajok Hilir Kabupaten Mempawah. Pontianak.

[15] Rosa dan Shalahuddin, M. 2018. Rekayasa Perangkat Lunak Terstruktur dan Berorientasi Objek. Bandung : Informatika.

[16] R Adwiya, ND Arizona, Y Yulia, MR Pambudi. 2019. Sales And Purchase Of Website Based Heavy Equipment Sparepart. Jurnal Teknologi dan Manajemen Informatika 5 (2). ISSN 2580-8044. 